\title{
Effect of load models on angular and frequency stability of low inertia power networks
}

DOI:

10.1049/iet-gtd.2018.5542

\section{Document Version}

Accepted author manuscript

Link to publication record in Manchester Research Explorer

\section{Citation for published version (APA):}

Adrees, A., \& Milanovic, J. V. (2018). Effect of load models on angular and frequency stability of low inertia power networks. IET Generation, Transmission and Distribution. https://doi.org/10.1049/iet-gtd.2018.5542

\section{Published in:}

IET Generation, Transmission and Distribution

\section{Citing this paper}

Please note that where the full-text provided on Manchester Research Explorer is the Author Accepted Manuscript or Proof version this may differ from the final Published version. If citing, it is advised that you check and use the publisher's definitive version.

\section{General rights}

Copyright and moral rights for the publications made accessible in the Research Explorer are retained by the authors and/or other copyright owners and it is a condition of accessing publications that users recognise and abide by the legal requirements associated with these rights.

\section{Takedown policy}

If you believe that this document breaches copyright please refer to the University of Manchester's Takedown Procedures [http://man.ac.uk/04Y6Bo] or contact uml.scholarlycommunications@manchester.ac.uk providing relevant details, so we can investigate your claim.

\section{OPEN ACCESS}




\title{
Effect of Load Models on Angular and Frequency Stability of Low Inertia Power Networks
}

\author{
Atia Adrees ${ }^{1}, \mathrm{~J}$ V. Milanović ${ }^{1 *}$ \\ ${ }^{1}$ School of Electrical and Electronic Engineering, The University of Manchester, Manchester, M60 1QD, UK \\ *atia.adrees@manchester.ac.uk
}

\begin{abstract}
This paper presents a thorough analysis of the effect of load models on frequency response, small and large disturbance stability of the power system, in order to identify the type of stability exhibiting the most sensitivity to load models, and for each type of studied stability, to pinpoint the load model that has the worst effect. The presented analysis shows clearly that transient stability is the most sensitive to load models. The number of unstable cases varies considerably with each type of studied load model. The effect of the load model magnifies with the reduction in headroom of synchronous generators. The results of the frequency response of the system following an active power disturbance demonstrate that the influence of constant power loads on the frequency response of the system can be significant if the system is operating with the reduced primary frequency response at high load. High integration of RES increases the variation in the damping of electromechanical modes due to increased uncertainties, and a high proportion of induction machines can reduce the damping of inter-area modes considerably, making a well stable mode unstable for certain operating points. The influence of load models has been illustrated using 68 bus NETS-NYPS system with $30 \%$ and $52 \%$ penetration of renewable energy sources.
\end{abstract}

\section{List of Abbreviations and Symbols}

$\begin{array}{cc}\text { RES } & \text { Renewable generation sources } \\ \text { SG } & \text { Synchronous generator } \\ \text { ZL } & \text { Constant impedance load } \\ \text { PL } & \text { Constant power load } \\ \text { PfL } & \text { Constant power load with frequency dependence } \\ \text { ZIP } & \text { ZIP load model } \\ \text { Cmp } & \text { Composite load model } \\ \text { PDF } & \text { Probability distribution function } \\ \text { FRT } & \text { Fault ride through } \\ f_{\text {nadir }} & \text { Frequency nadir } \\ \text { RoCoF } & \text { Rate of change of frequency } \\ \text { DFIG } & \text { Doubly fed induction generator } \\ \text { FCC } & \text { Full converter connected }\end{array}$

\section{Introduction}

It has been recognized by both industry and academia that load characteristics have a significant influence on both steady-state and dynamic performance of power systems. A lot of work has been done in the area of load modelling over past decades [1-4].

The effect of load models (dynamic, composite and exponential) and their parameters on the damping of electromechanical modes has been widely studied and reported in [5-7]. The results of time domain simulation analysis of field measurements data of the Taiwan power system showed that in the case of unstable low-frequency oscillations event, a dynamic load model gives the largest oscillation, followed by the composite load model and then the exponential load model [5].

Although, it is well known that load characteristics can have a significant effect on the rates of acceleration or deceleration of individual generators during the fault and, therefore, on the eventual stability of the system [8], very few studies have discussed the impact of load models on transient stability $[8,9]$.

The effect of load models on frequency stability is completely unexplored. It is general practice in frequency 


\section{ACCEPTED VERSION OF THE PAPER}

stability studies to look at the collective performance of all generators in the network. The effects of the system loads are lumped into a single damping constant $D$. The speed of the equivalent generator represents the system frequency [10-12].

The proliferation of wind and solar power generation in electric power networks in various countries around the world indicates that these are the fastest growing renewable technologies $[13,14]$. These renewable energy sources (RES) are characterized by a converter connected interface, their intermittency, and non-controllable behaviour. The converted connected RES does not contribute to system inertia and affects the dynamic behaviour of the power system in a way that is different from conventional synchronous generators (SG) following a disturbance. SG can supply high short circuit currents to the fault location and hold the voltage in the power system so that the low voltage area is reduced [15]. Like a STATCOM, the line side converter can regulate its terminal voltage by injecting reactive currents independently of the active power. However, the maximum reactive currents are limited by the maximum rating of the converter [16]. The high integration of RES affects power flows, voltage, and frequency in power networks. Loads have always had a degree of uncertainty associated with them that will further diversify in the future due to the proliferation of the electric vehicle. The high integration of RES in power networks adds another layer of uncertainty resulting in increased uncertainties in power system operations. A number of studies are performed to assess the impact of the increased penetration of RES on grid frequency and angular stability of the system $[13,14,17-19]$. Authors previous works included frameworks to estimate the critical inertia limits for grid frequency and effect of renewable penetrations on transient stability [20, 21]. The extent of the influence of load models on angular stability, and the frequency response of the power system with increased uncertainties and changed dynamic behaviour due to RES, is entirely unexplored. The paper aims to provide a thorough analysis of the impact of load characteristics on frequency and angular stability of power systems with a high proportion of RES. The studies identify the load types which lead to the most optimistic and the most pessimistic results for each type of stability. Finally, the paper identifies the type of stability that is most sensitive to load models in power systems with a high proportion of RES.

\section{Load Models}

Existing load models can be broadly grouped into two categories -static and dynamic. Further details on load modelling and load models can be found in [1]. The studies within this work are performed with the most frequently used models in industrial practice [4] and are briefly discussed below:-

\subsection{Static load models}

Static load models describe the relationship between active and reactive power consumed by the load as an algebraic function of voltage and frequency.

\subsubsection{Exponential load model:}

The most frequently used static load model is the exponential load model [22], given by (1)

$$
\begin{aligned}
& P=P_{n}\left(\frac{U}{U_{n}}\right)^{k p u}\left(\frac{f}{f_{n}}\right)^{k p f} \\
& Q=Q_{n}\left(\frac{U}{U_{n}}\right)^{k q u}\left(\frac{f}{f_{n}}\right)^{k q f}
\end{aligned}
$$

Where $P$ and $Q$ are the real and reactive power drawn by the load at voltage $U$ and frequency $f . P_{n}$ and $Q_{n}$ are the real and reactive power drawn at rated voltage $U_{n}$ and nominal frequency $f_{n}$. The exponents $k_{p u}, k_{q u}, k_{p f}$, and $k_{q f}$ describe the changes in load demand in response to variations in the supply voltage and grid frequency. The effect of constant power (PL) and constant impedance (ZL) load models are studied within this work. The sensitivity of the load to frequency and voltage is determined usually by continuously measured data (data captured at a high sampling rate)". The details can be found in [1].

\subsubsection{ZIP model:}

Another static load model frequently used is the second-order polynomial model. The variant with frequency dependence neglected

$$
\begin{aligned}
& P=P_{n}\left[p_{1}\left(\frac{U}{U_{n}}\right)^{2}+p_{2}\left(\frac{U}{U_{n}}\right)+p_{3}\right] \\
& Q=Q_{n}\left[q_{1}\left(\frac{U}{U_{n}}\right)^{2}+q_{2}\left(\frac{U}{U_{n}}\right)+q_{3}\right]
\end{aligned}
$$

The parameters $p_{1}$ and $q_{1}$ represent the relative participation of constant impedance, $p_{2}$ and $q_{2}$ correspond to the relative participation of constant current load, and $p_{3}$ and $q_{3}$ represent the relative participation of constant power load.

\subsection{Dynamic load models}

Dynamic loads exhibit time-dependent responses which are determined by the previous conditions of both the system and the load itself. The exponential dynamic load model, the transfer function model of the induction motor and the dynamic model of an induction motor, are the most commonly used dynamic models [1]. The exponential dynamic load model is typically used when the proportion of residential load in the total load is significant, and the participation of induction motors in the load mix is small $[23,24]$. The load at most bulk buses is a combination of different static and dynamic devices; especially at buses that supply industrial load, hence a model should incorporate both static and induction model components [25]. A composite load model consisting of an induction motor in parallel with static load is used to represent this type of load in this work [25]. In some countries, in particular those that are economically well developed, participation of induction motors in the total load demand can be $60-70 \%$ [1], therefore, a composite load model combining static dynamic $(30 \%-70 \%)$ is used.

\section{Methodology}

The framework to assess the effect of load models considering the uncertainties in low inertia system is presented in Fig. 1. In order to study the effect of load 


\section{ACCEPTED VERSION OF THE PAPER}

models on frequency and angular stability of the system, a dynamic model of the test network, including RES units, is developed in DIgSILENT/PowerFactory. The loads are represented by ZL model. Uncertainty in wind and PV power generation and load forecast are sampled using appropriate probability distribution functions $(p d f s)$, and optimal power flow (OPF) is performed to determine the power dispatches of SG. Finally, the simulations are performed by introducing an active power disturbance in the system, and grid frequency at all synchronous generation buses, and the buses connected to tie-lines are recorded. Frequency nadir $f_{\text {nadir }}$ and $\mathrm{RoCoF}$ are calculated in each simulation.

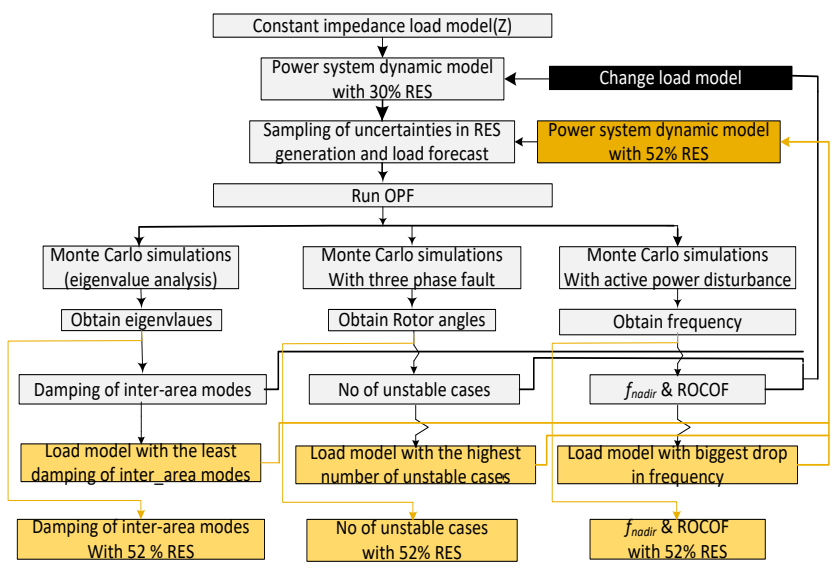

Fig. 1: Flowchart of the methodology

For transient stability analysis the same set of uncertainties in RES generation and load forecast is used. The fault location is modelled using a uniform distribution which means that the probability of fault on the lines in the test network is the same. A normal distribution with a mean value of 11 cycles and a standard deviation of $6.67 \%$ is used to model the fault duration. The rotor angles of each generator are stored as the output of each simulation and are used to calculate the number of unstable cases.

To study the effect of load models on small disturbance stability, eigenvalue analysis is performed with the same uncertainties in RES generation and load forecast. The frequencies and damping of all electromechanical modes are recorded in each simulation.

Once the performance of the network with the $\mathrm{ZL}$ model is established, the load model is changed to constant power, frequency response and rotor angle stability analysis is performed again. It is to be noted that the uncertainties in RES power generation and load forecast remains the same with each load model. The process is iterated for the ZIP and composite load models.

The results for individual load models are compared for frequency and rotor angle stability. The load model exhibiting the biggest drop in frequency is selected to perform the frequency analysis with a high penetration of RES. The load model leading to the highest number of unstable cases is selected for transient stability, and the load model resulting in the most reduction in damping of electromechanical modes is chosen for small disturbance stability.

The penetration of RES is increased to $52 \%$ in the network. Uncertainty in wind and PV power generation and load forecast are sampled again, and optimal power flow
(OPF) is performed to determine the power dispatches of SG. The frequency response and rotor angle stability analysis is performed with a constant impedance model and selected load models.

\section{Test system}

The test system within this work is the modified version of the reduced order equivalent model of the New England Test System (NETS) and the New York Power System (NYPS) [26]. The network consists of five areas, NETS (G1-G9), NYPS (G10-G13) and three distinct areas represented by G14, G15, and G16. All generators, except for generator G9, are under slow excitation (IEEE DC1A). G9 is equipped with a fast-acting static exciter (IEEE STIA) and power system stabilizer (PSS). All generators in the network are equipped with governor systems. SGs are represented by sixth order models. Transmission lines are modelled with the standard $\pi$ circuits.

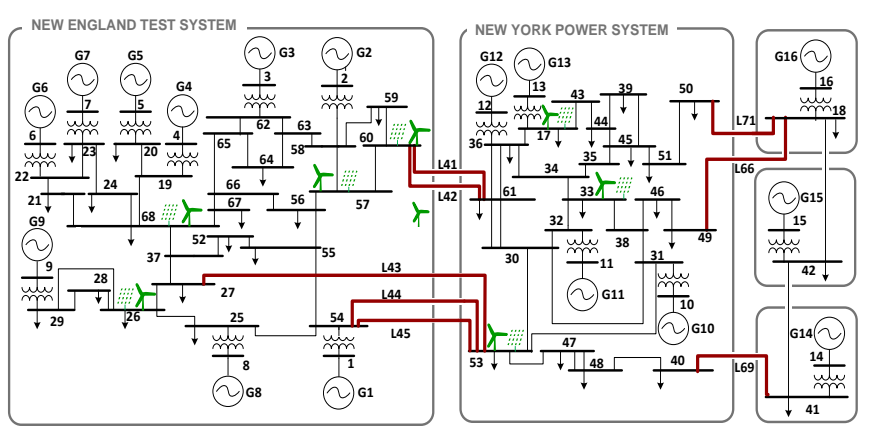

Fig. 2: Modified IEEE 68 bus system

The conventional part of the network is adopted from [26]. Seven RES units are connected to the buses shown in Fig. 2. The buses for the connection of RES are chosen to have a minimum effect on power flows and the voltage profile of the network. The load parameters are taken from [1].

\subsection{RES Models}

A generic type 3 model is used in this paper to represent DFIGs. The structure of the model is similar to the one proposed by WECC and IEC [27, 28], and is available in DIgSILENT - PowerFactory. It takes into account the aerodynamic part and the shaft of the wind turbine generator (WTG) as well as the pitch control of the blades. The rotor side converter controller is modelled, including relevant limitations, ramp rates and protection mechanisms, such as the crowbar. The DFIG is represented by a typical 2 nd order model of an induction machine neglecting the stator transients and including the mechanical equation [22]. The rotor side converter controls the voltage in the rotor as in [29]. Therefore, the model represents all the relevant parts that influence the dynamic behaviour of DFIGs.

A type 4 wind generator model is used to represent all full converted connected (FCC) units. Both wind generators and PV units can be represented by a type 4 model in stability studies since the converter decouples the dynamics of the generator [29, 30]. This is also suggested by the WECC Renewable Energy Modeling Task Force [30]. 


\section{ACCEPTED VERSION OF THE PAPER}

Both DFIGs and FCC are handled as aggregated units. All RES units have Fault Ride Through (FRT) capabilities and remain connected during the fault. The amount of connected RES for each area of the system, i.e., the installed capacity of RES, is given as a percentage of the total installed conventional generation capacity of that area before adding any RES. Eigenvalue analysis and all dynamic simulations are performed using DIgSILENT PowerFactory software. All dynamic simulations are RMS simulations.

\subsection{Modelling of uncertainties}

\subsubsection{Uncertainty in load forecast:}

The uncertainty in the load forecast is represented by a normal distribution, with a standard deviation of $3.34 \%$, around the nominal operating point.

\subsubsection{Uncertainty in wind and PV generation:}

A Weibull distribution with $\alpha=2.2 \& \beta=11.1$ is used to account for the uncertainty in the output power of the wind farm. It is assumed that all PV plants follow a beta distribution with $a=13.7$ and $b=1.3$.

(Note: Other distributions including conditional loading or historical data can be used to represent load, wind, and PV power generation uncertainties without loss of generality of the proposed approach.)

In order to establish the viable operating point of the system, the distributions are sampled separately for each load, wind and solar plant in a similar manner as [31]. After considering the uncertainties, an optimal load flow solution is then used to determine the corresponding output of SG.

\subsubsection{Uncertainty in fault location and fault duration:}

A uniform distribution is used to model fault location which means that the probability of fault on the lines in the test network is the same. A normal distribution with a mean value of 11 cycles and standard deviation of $6.67 \%$ is used to model the fault duration.

\subsection{Case studies}

CS I: $30 \%$ SG is replaced by RES in NETS and NYPS area. The average inertia of the system is $6.8 \mathrm{~s}^{1}$.

CS II: In CS I network, the load is reduced to $40 \%$. $2 / 3$ rd reduction in load is balanced by disconnecting $S G$ and $1 / 3$ by de-loading SG. The penetration level increases to $52 \%$ (in NETS and NYPS area) and the average inertia of the system reduces to $2.86 \mathrm{~s}$.

CS III: In CS I network (30\% RES), the load of the network is reduced to $40 \%$. All reduction in load is met by de-loading SG. Hence, the inertia of the system remains the same as in CS I, but PFR is increased by 8 times, due to increased headroom of SGS, in CS III.

CS IV: In CS II network, the governors of G14 and G16 are blocked. This reduces PFR to nearly the same

\footnotetext{
${ }^{1}$ Including UK, many other countries have a binding target of $30 \%$ final energy consumption from RES by 2020 . Therefore, $30 \%$ proportion of RES is used as a base case
}

amount as in CS I. The inertia of the system stays the same as it is in CS II.

CS I is repeated with each type of model with the same uncertainties for frequency response and rotor angle stability of the system. CS II is performed only with ZL and the load model showing the most significant change in performance parameter, i.e., frequency nadir, number of unstable cases, damping of electromechanical modes.

CS I differs from CS II in three aspects:- i) The average headroom of SGs in CS II is increased by 1.4 times than the average headroom of SGs in CS I. Hence primary frequency response (PFR) is increased. ii) In CS II, the total load in the network is $40 \%$ of the load in CS I iii) CS II has lower inertia than CS I.

To clarify that the variation in the effect of the load model due to PFR, CS III and CS IV, are developed.

Table 1 summarises CS performed within the paper. Table 1: Case studies performed within this paper

\begin{tabular}{llll}
\hline \hline CS & \multicolumn{3}{c}{ Load Model } \\
\cline { 2 - 4 } & $\begin{array}{l}\text { Frequency } \\
\text { stability }\end{array}$ & $\begin{array}{l}\text { Small disturbance } \\
\text { stability }\end{array}$ & $\begin{array}{l}\text { Large disturbance } \\
\text { stability }\end{array}$ \\
\hline \hline CS I & $\begin{array}{l}\text { ZL, PL, P } \\
\text { ZIP and CMP }\end{array}$ & $\begin{array}{l}\text { ZL, PL, PfL, ZIP } \\
\text { and CMP }\end{array}$ & $\begin{array}{l}\text { CS I: ZL, PL, PfL, } \\
\text { ZIP and CMP }\end{array}$ \\
\hline CS II & ZL \& PL & ZL, CMP & ZL \&PL \\
\hline CS III & ZL, PL & - & - \\
\hline CS IV & ZL, PL & - & - \\
\hline \hline
\end{tabular}

\section{Results and analysis}

\subsection{Frequency stability}

An active power disturbance of $800 \mathrm{MW}$ which is $3 \%$ of the peak load of $26.8 \mathrm{GW}$ is introduced. Due to modelled uncertainties in RES generation and load forecast, the disturbance varies by $\pm 10 \%$. Frequency nadir (the minimum frequency) $f_{\text {nadir }}$ and the rate of change of frequency (RoCoF), following the disturbance, are recorded on each bus directly connected to tie-lines and synchronous generation buses. It is important to note $f_{\text {nadir }}$ is not significantly different on the buses in the NETS and NYPS area. Since the disturbance is introduced in the NETS area and L41 is transferring the highest power, $f_{\text {nadir }}$ and RoCoF results at bus 60 are discussed throughout this work.
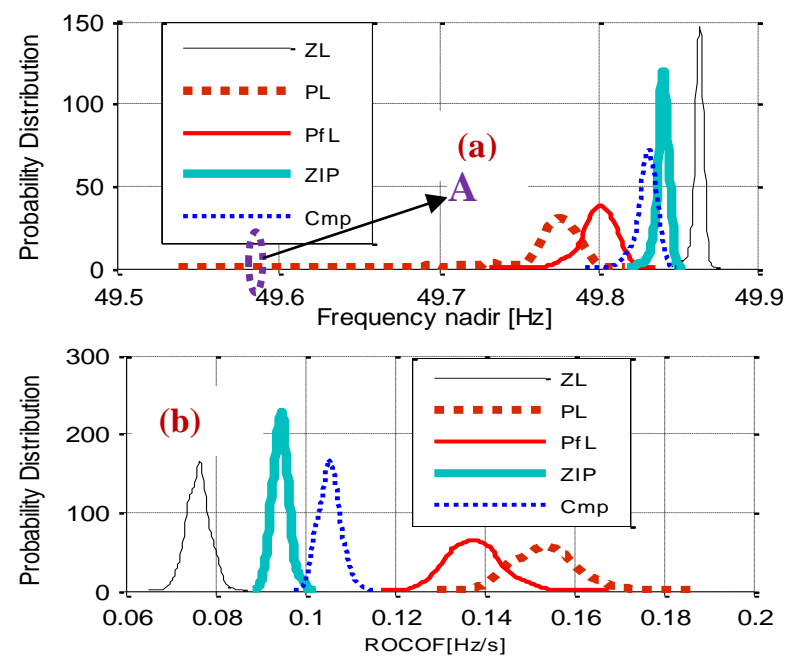


\section{ACCEPTED VERSION OF THE PAPER}

Fig. 3: 30\% RES in the system (a) Effect of load models on $f_{\text {nadir }}$ (b) Effect of load model on RoCoF

Fig. 3 (a) shows $p d f s$ of $f_{\text {nadir }}$ with each type of studied load model, and Table 2 summarizes the statistical analysis of Fig. 3 (a). $f_{\text {nadir }}$ is governed by system inertia, the amount of generation lost and governor response. In each simulation, the inertia of the system stays the same. However, the size of the disturbance varies by $\pm 10 \%$ due to modelled uncertainties in RES generation and load forecast. The headroom of generators also varies due to the variation in load and RES power generation.

Table 2: Statistical analysis of Fig. 3

\begin{tabular}{lcc}
\hline & Mean & Range \\
Constant Impedance (ZL) & 49.86 & 0.027 \\
\hline Constant Power(PL) & 49.78 & 0.28 \\
Constant Power with frequency dependence(PfL) & 49.8 & 0.103 \\
[ZIP] & 49.83 & 0.035 \\
Composite load (static+ induction machine)(Cmp) & 49.82 & 0.057
\end{tabular}

By looking at (Table 2) mean values of $p d f s$, it can be observed that the largest drop in $f_{\text {nadir }}$ is observed with the PL model. The mode of pdf of $f_{\text {nadir }}$ with PL occurs at 49.78 $\mathrm{Hz}$, and the $p d f$ spread is $0.28 ; f_{\text {nadir }}$ varies between $49.82 \mathrm{~Hz}$ - $49.54 \mathrm{~Hz}$. When frequency dependence is added in loads, the mode shifts to $49.8 \mathrm{~Hz}$ and spread of $p d f$ reduces to 0.103 . The mode of $f_{\text {nadir }} p d f$ shifts to $49.82 \mathrm{~Hz}$ when all loads are represented by the composite load model. The composite load model consists of 30\% static load and $70 \%$ dynamic (induction machine) load. Induction machines add inertia to the system; their speed reduces as frequency drops. This improves $f_{\text {nadir }}$, and the spread of frequency nadir $p d f$ becomes 0.057. Further improvement in frequency nadir $p d f$ is observed when all the loads in the network are represented by the ZIP model. The mode of the $p d f$ moves to $49.83 \mathrm{~Hz}$ and the range of $p d f$ becomes 0.035 . The mode of $p d f$ with ZL shows the smallest drop, as expected, $f_{\text {nadir }}$ improves to $49.86 \mathrm{~Hz}$, the $p d f$ becomes very narrow, and the range becomes 0.027 . Constant impedance loads reduce the active power consumption as the bus voltage deviates below $1 \mathrm{pu}$ and increase power consumption when the volatge increases above per unit, hence, providing damping to frequency excursions.

The RoCoF is directly proportional to the active power disturbance and inversely proportional to the inertia of the system. The RoCoF measured within tens of ms after the disturbance is the same with each type of load model. However, it starts to vary as the measurement time increases. The RoCoF presented in Fig. 3 (b) is measured after 20 cycles. It can be observed that there is a small variation in RoCoF due to different types of load model. The smallest values of RoCoF occur with the ZL load model and the largest with the PL model.

Since the largest drops in $f_{\text {nadir }}$ are observed with the PL model, CS II is performed with ZL and PL models, and $p d f s$ of $f_{\text {nadir }}$ and RoCoF are presented in Fig. 4. In CS II, the average inertia of the system reduces due to the disconnection of SG, leading to bigger drops in frequency following the same active power disturbance. It can be noticed (Fig. 4) that the modes of $f_{\text {nadir }} p d f s$ have moved to lower frequencies. However, $p d f$ of $f_{\text {nadir }}$ generated with ZL overlaps to a large extent the $p d f$ produced with the PL model. The RoCoF pdfs for CS II show the same behaviour. In CS I, the $p d f s$ of $f_{\text {nadir }}$ and RoCoF with PL and ZL models are distinct and do not overlap with each other.
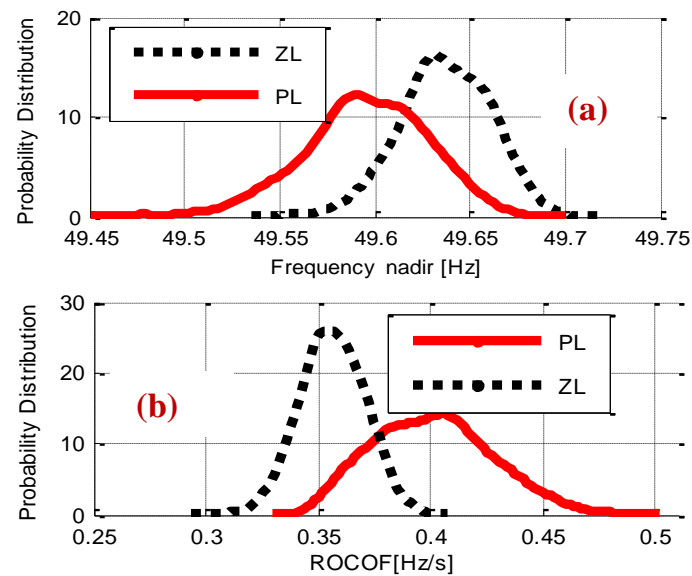

Fig. 4: 52\% RES in the system a) Effect of PL and ZL on $f_{\text {nadir }}$ (b) Effect of PL and ZL on RoCoF

CS I differs from CS II in three aspects:- i) The average headroom of SGs in CS II is increased by 1.4 times than the average headroom of SGs in CS I. Hence primary frequency response (PFR) is increased. ii) In CS II, the total load in the network is $40 \%$ of the load in CS I iii) CS II has lower inertia than CS I.

To clarify that the variation in the effect of the load model is due to PFR, two additional case studies are developed.

CS III: In CS I network (30\% RES), the load of the network is reduced to $40 \%$. All reduction in load is met by de-loading SG. Hence, the inertia of the system remains the same as in CS I, but PFR is increased by 8 times, due to increased headroom of SGS, in CS III.

CS IV: In CS II network, the governors of G14 and G16 are blocked. This reduces PFR to nearly the same amount as in CS I. The inertia of the system stays the same as it is in CS II.

The simulations for CS III and CS IV are performed with the uncertainties used in CS II.
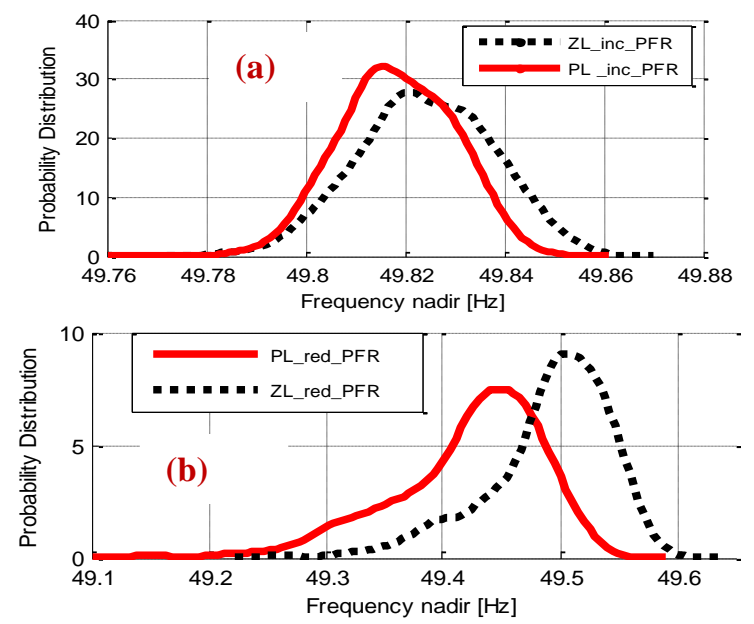


\section{ACCEPTED VERSION OF THE PAPER}

Fig. 5: Comparison of ZL and PL models on frequency nadir (a) increased PFR, CS III (b) reduced PFR, CS IV.

The $p d f s$ of $f_{\text {nadir }}$ with ZL and PL for CS III (Fig. 5- a) overlap, as expected the effect of the load model has decreased significantly due to increased PFR. A close comparison of Fig. 5- a, and Fig. 3 -a shows that for the same inertia, the drop in frequency with ZL is slightly increased when the load is reduced to $40 \%$. The decrease in the total load also reduces the amount of damping offered by the loads, hence, a slightly bigger drop in frequency is observed.

Fig. 5 (b) shows $p d f s$ of $f_{\text {nadir }}$ for CS IV. It can be seen that $p d f s$ of $f_{\text {nadir }}$ overlap even now, though PFR is reduced to the same amount in CS I. This indicates that the effect of load models on frequency response of the system is decreased as the total load of the network is reduced.

In this paper, an active power disturbance is introduced by simulating an outage of a generator which is a standard practise for frequency stability analysis. There are increasing concerns about frequency stability or frequency regulation with increasing penetration RES. RES displaces SGs in power networks that reduce the available kinetic energy, hence, the natural inertia of the system. The primary frequency response requirement increases exponentially with the reduction in inertia. During an active power disturbance accompanied by a voltage dip, converter connected RES may reduce their active power to provide reactive power to the grid due to fault ride through characteristics that can increase the size of potential contingency. (Though, line-side converter can regulate its own terminal voltage by injecting reactive current independently of the active power. However, the maximum reactive currents may be limited by the active power production of the turbine due to the limited maximum current rating of the converter.) Therefore, frequency regulation following loss of generation is the main concern in future power networks.

To demonstrate that frequency regulation with RES is of more concern following a loss generation compared to loss of load, the operating point of the network corresponding to Point A in Fig. 4(a) is chosen. Fig.6 and Fig.7 show frequency excursions with constant power and constant impedance load model following the loss of load and loss of generation respectively. The size of the disturbance is the same in both cases.

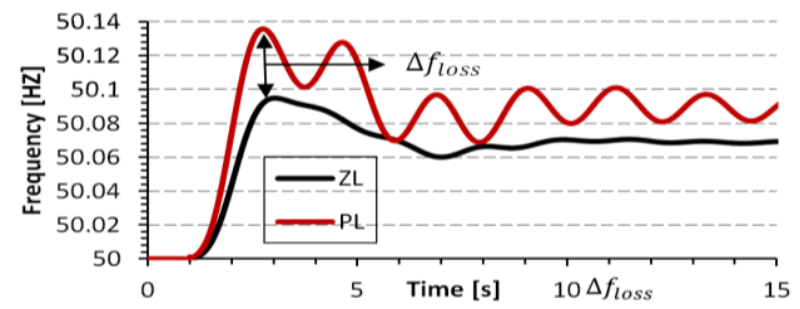

Fig. 6: Frequency deviation following 3\% increase in total load

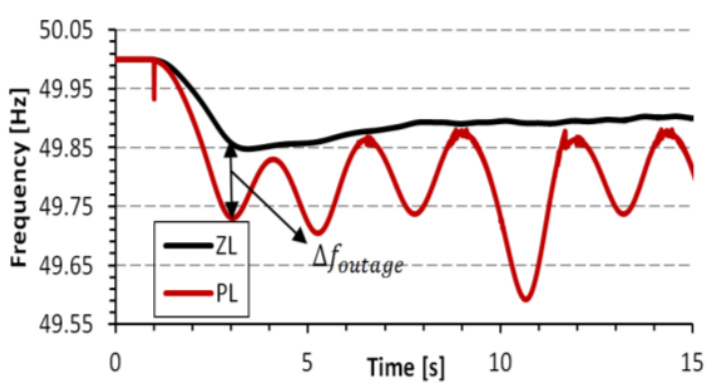

Fig. 7: Frequency deviation following $3 \%$ increase in total load

The initial frequency deviation indicated in Fig. 7, $\Delta f_{\text {outage }}=0.1 \mathrm{~Hz}>\Delta f_{\text {loss }}=0.5 \mathrm{~Hz}$ in Fig. 6. Following the outage of the generator frequency has a second bigger drop after $10 \mathrm{~s}$, this is due to G16 slipping the ploe and getting disconnected from the grid.

However, following the $3 \%$ loss in the total load, frequency with constant power load increases to 50.14 and then starts settling down at 50.08 and no generator losses synchronsim.

Table 3 summarizes the effect of load models and ranks the loads based on the severity of frequency nadir in descending order. Table 3: Ranking of load models and the summary of effect of load models on frequency stability

\begin{tabular}{|c|c|}
\hline $\begin{array}{l}\text { Load model } \\
\text { Ranking } \\
\text { based on } \\
\text { severity }\end{array}$ & Effect of load model on frequency stability \\
\hline i. $\mathrm{PL}$ & $\begin{array}{l}\text { - } f_{\text {nadir }} \text { and RoCoF obtained with ZL model can be very } \\
\text { conservative at high load of the network. }\end{array}$ \\
\hline ii. $\mathrm{CMP}$ & $\begin{array}{l}\text { - Increased PFR at high load reduces the effect of load } \\
\text { models on } f_{\text {nadir. }}\end{array}$ \\
\hline iii. ZIP & - As the penetration of RES increases at low load of \\
\hline iv. $\mathrm{ZL}$ & dynamics decreases considerably. \\
\hline
\end{tabular}

\subsection{Small disturbance stability}

CS1 is repeated for small disturbance stability analysis using the same uncertainties in RES generation and load forecast for each studied load type. Fig. 7 (a) shows the location of least damped inter-area modes. The frequencies and damping of inter-area modes remain nearly the same when CS I is repeated with ZL, PL, and then with ZIP models. However, frequencies and damping of electromechanical modes vary considerably when all the loads in the network are represented by a composite load model consisting of $30 \%$ static, and $70 \%$ dynamic load represented by induction machines.

The arrows in Fig. 7 (a) indicate the direction of movement of modes due to the composite load model. The damping of four modes is reduced, and one is slightly improved with the composite load model. The 0.45-0.5 Hz mode $\left(\mathrm{M}_{1}\right)$ even becomes unstable for a few operating points. Though the composite load model decreases the variation in frequency of each mode due to uncertainties in the system, the damping of the modes in most cases is reduced.

The most probable value of the damping of higher frequency mode $\left(\mathrm{M}_{1}\right)$ with $\mathrm{ZL}$ is at $-0.23 \mathrm{~s}$ which moves to $0.07 \mathrm{~s}(69 \%$ reduction) when all loads are modelled as 


\section{ACCEPTED VERSION OF THE PAPER}

composite loads. The most probable value of lower frequency mode $\left(\mathrm{M}_{2}\right)$ with $\mathrm{ZL}$ model is at $-0.48 \mathrm{~s}$ which moves to $-0.15 \mathrm{~s}$ when all loads are represented by the composite load model. The percentage decrease in the damping is nearly the same, i.e., $68 \%$.
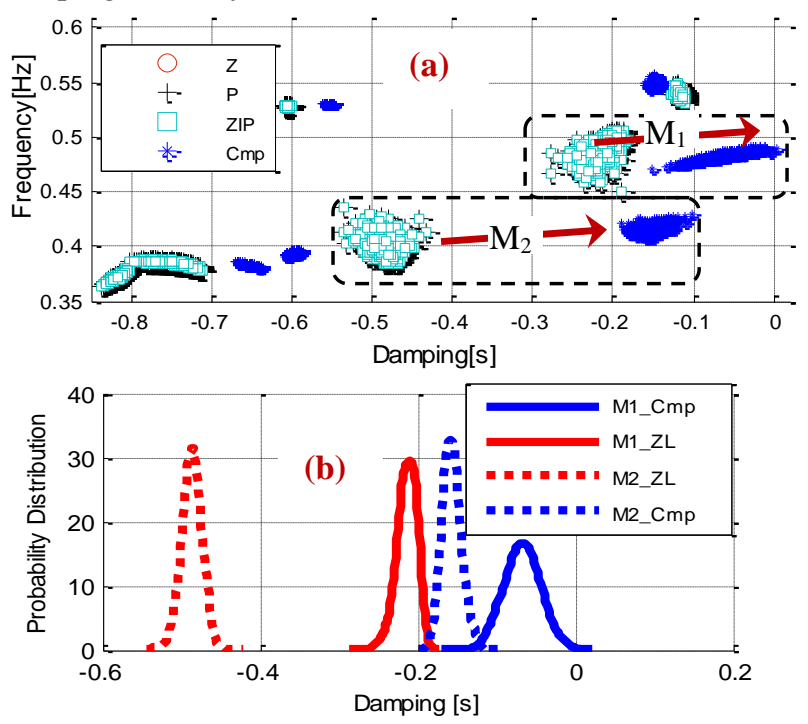

Fig. 7: (a) Location of inter-area modes with different load models, $30 \%$ penetration of RES (b) pdfs of damping of $M_{l}$ and $M_{2}$

CS II is performed with $\mathrm{ZL}$ and then with the composite load model. The scatter plot of the location of least damped inter-area modes is presented in Fig. 8 (a). It can be seen that in CS II the damping of all the studied interarea modes is reduced.
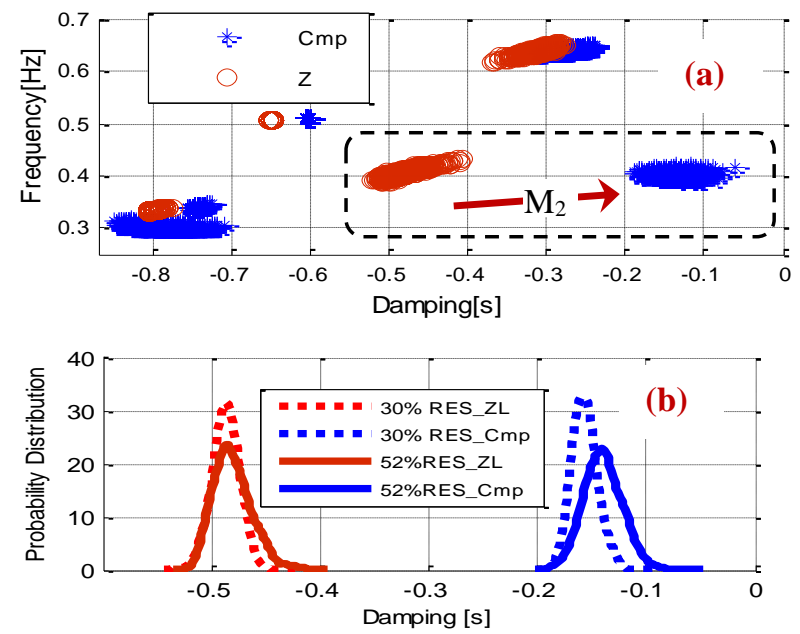

Fig. 8: (a) Variation in the damping of inter-area modes due to $30 \%$ RES with $Z$ and composite load models (b) Effect of increased penetration on the damping of $M_{2}$ with ZL and PL

Fig. 8 (b) shows the impact of the increased penetration of RES on the damping of the mode $\mathrm{M}_{2}$ with $\mathrm{ZL}$ and PL models. It can be observed that the effect of increased penetration of RES on the damping of the studied electromechanical modes with the ZL model is negligible. The damping of the studied mode is reduced, and the range of variation is increased with the composite load model due to increased shares of RES. The most probable value of $p d f$ of damping of the critical mode with the composite load model occurs at -0.15 when the network is operating with $30 \%$
RES penetration and this shifts to $-0.13 \mathrm{~s}$ with the same load model when RES penetration increases to $52 \%$.

The damping of electromechanical modes is affected by fast controls; power flows between areas and load characteristics. RES penetration levels increase to $52 \%$ at $40 \%$ loading of the network; this reduces the power flow through tie-lines. Typically, damping of inter-area modes increases as the power transfer through tie-lines decreases. However, in this case, a small reduction in the damping of the mode with the composite load model is observed, and the damping of the studied inter-area mode nearly remains the same with the constant impedance load model for both penetration levels, i.e., $30 \%$ and $52 \%$.

The effect of dynamic load model on the damping of inter-area modes decreases as their proportion decreases in the composite load model. Fig. 9 shows the variation in the damping of inter-area modes when the proportion of dynamic load model reduces from $70 \%$ to $30 \%$. It can be seen that the damping of modes with ZL overlap the damping with composite load model when the proportion of dynamic load reduces to $30 \%$.

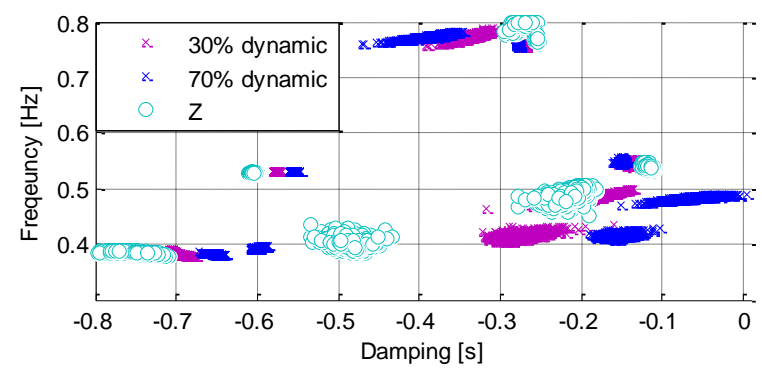

Fig. 9: The effect of increased proportion of dynamic load model on the damping of inter-area modes

Based on the analysis within the paper, it can be concluded that high proportion of dynamic load model have a potential to considerable reduce the damping of inter-area modes when the network is operating at high load. Therefore, it is important to know the composition of load at high network load operating points by performing field measurements.

Table 4: Ranking of load models based on severity of results and summary of effect of load models on small disturbance stability.

\begin{tabular}{l||l}
\hline \hline $\begin{array}{l}\text { Load model ranking } \\
\text { based on damping } \\
\text { of inter-area modes }\end{array}$ & $\begin{array}{l}\text { Effect of load models on the damping of inter- } \\
\text { area modes }\end{array}$ \\
\hline \hline i. CMP & $\begin{array}{l}\text { - The variation in the damping of inter-area } \\
\text { load models is negligible when load models } \\
\text { are switched from ZL to ZIP and to PL. }\end{array}$ \\
ii. $\mathrm{ZL} \approx \mathrm{ZIP} \approx \mathrm{PL}$ & $\begin{array}{l}\text { Dynamic load models can significantly } \\
\text { reduce the damping of inter-area modes when } \\
\text { the system is operating at high load. }\end{array}$ \\
\hline
\end{tabular}

\subsection{Large disturbance stability}

Only three phase self-clearing faults are considered in this work. The transient stability index is used to assess 


\section{ACCEPTED VERSION OF THE PAPER}

the effect of load models on large disturbance rotor angle stability.

$$
T S I_{i}=\frac{360-\delta_{\max , i}}{360+\delta_{\max , i}}
$$

Where $\delta$ max, $i$ is the maximum separation between the rotor angles of any two generators. This index provides a general overview of overall system dynamic behaviour for the specific contingency. Negative values of the index indicate that the separation between the rotor angles of at least two generators is greater than 360 degrees and the system is unstable.

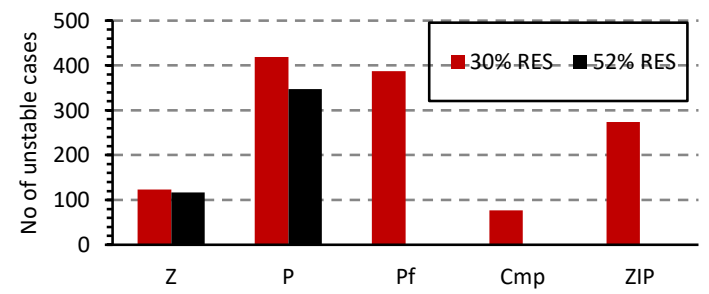

Fig. 10: No of unstable cases with ZL, PL, P $\mathrm{f}, Z$ ZIP and composite load model with $30 \%$ RES, and ZL and PL for $52 \%$ penetration of RES.

It can be seen that the number of unstable cases with the same uncertainties varies significantly with the load model. The number of unstable cases is highest (419) with the PL model and lowest with the composite load model. The inclusion of frequency dependence in the PL model reduces unstable cases by $7.6 \%$, i.e., from 419 to 387.Although, the system exhibits the least number of first swing unstable cases with the composite load model, the damping of oscillations is significantly reduced with this model.

As the number of unstable cases is the highest with the PL model, CS II is performed with PL, and then with ZL. The number of unstable cases reduces from 123 to 117 (4\% reduction) with the ZL model and 419 to 387 (17\%) with the PL model. In CS II, RES penetration is 52\%, the average inertia of the system is $2.2 \mathrm{~s}$, and average headroom of generators (lightly loaded) is greater than a CS I. In this work, all RES units are considered to have FRT (fault ride through) capability. RES operating with FRT increases their reactive power output following a disturbance to provide support to the system. In general, this operation can improve the transient stability. This extent of improvement varies with the type of load model.

Table 5: Ranking of load models based on severity of results and summary of effect of load models on large disturbance stability

\begin{tabular}{cl||l}
\hline $\begin{array}{l}\text { Load model ranking } \\
\text { based on number of } \\
\text { unstable cases. }\end{array}$ & $\begin{array}{l}\text { Effect of load models on the large } \\
\text { disturbance stability }\end{array}$ \\
\hline \hline i. PL & - The number of unstable case varies \\
ii. ZIP & $\begin{array}{l}\text { significantly with the load model. } \\
\text { - The high proportion of dynamic load model } \\
\text { iii. ZL } \\
\text { iv. CMP }\end{array}$ & $\begin{array}{l}\text { reduces significantly the number of unstable } \\
\text { cases. }\end{array}$ \\
\hline \hline
\end{tabular}

\section{Conclusions}

This paper presented an analysis of the effect of load models on frequency and rotor angle stability.

The results obtained show clearly that large disturbance rotor angle stability is the most sensitive to load models. The number of unstable cases varies considerably with each type of studied load model, and it is the lowest with the composite load model, and the highest with constant power load. The increased penetration of renewables with fault ride through capability slightly improves large disturbance rotor angle stability, principally due to the increased headroom of de-loaded synchronous generators, and the extent of this improvement is different with different types of load model.

The results of the small disturbance stability analysis show that frequencies and damping of inter-area modes are notably affected only by the composite load model which can lead to a substantial reduction in the damping of critical inter-area modes, irrespective of the level of RES penetration in the network.

Finally, performed analysis of frequency response demonstrated that the constant power model is the most detrimental to frequency stability and leads to the largest frequency nadir and RoCoF. The effect of load models on the frequency response of the system can be significant if the system is operating with the low inertia and reduced primary frequency response due to the high penetration of RES. In such cases, the frequency nadir and the RoCoF become much more sensitive to load modelling, and variation can be substantial if the proportion of the constant power load is high. Furthermore, their sensitivity to other system uncertainties also increases.

\section{Acknowledgments}

This work is supported by EPSRC - China collaborative project RESTORES and EPSRC India collaborative project JUICE.

\section{References}

[1] J. Milanović, J. Matevosiyan, A. Borghetti, S. Djokić, and Z. Dong, "Modelling and aggregation of loads in flexible power networks," CIGRE Taskforce WG C4. 605, Technical Brochure, vol. 566, 2014.

[2] Z. Dong, A. Borghetti, K. Yamashita, A. Gaikwad, P. Pourbeik, and J. Milanovic, "CIGRE WG C4. 605 recommendations on measurement based and component based load modelling practice," CIGRE SC, vol. 4, p. 2012, 2012.

[3] P. Regulski, D. S. Vilchis-Rodriguez, S. Djurović, and V. Terzija, "Estimation of Composite Load Model Parameters Using an Improved Particle Swarm Optimization Method," IEEE Transactions on Power Delivery, vol. 30, pp. 553-560, 2015.

[4] J. V. Milanovic, K. Yamashita, S. M. Villanueva, S. Ž. Djokic, and L. M. Korunović, "International industry practice on power system load modeling," IEEE Transactions on Power Systems, vol. 28, pp. 3038-3046, 2013.

[5] W.-S. Kao, "The effect of load models on unstable lowfrequency oscillation damping in Taipower system experience w/wo power system stabilizers," IEEE Transactions on Power Systems, vol. 16, pp. 463-472, 2001.

[6] J. V. Milanovic and I. A. Hiskens, "Effects of load dynamics on power system damping," IEEE Transactions on Power Systems, vol. 10, pp. 1022-1028, 1995.

[7] N. Martins, S. Gomes, R. M. Henriques, C. B. Gomes, A. d. A Barbosa, and A. C. B. Martins, "Impact of induction motor loads in system loadability margins and damping of inter-area modes," 


\section{ACCEPTED VERSION OF THE PAPER}

in 2003 IEEE Power Engineering Society General Meeting (IEEE Cat. No.03CH37491), 2003, pp. 1-1384 Vol. 3.

C. Concordia and S. Ihara, "Load Representation in Power System Stability Studies," IEEE Transactions on Power Apparatus and Systems, vol. PAS-101, pp. 969 - 9771982.

[9] J. Gim, T. Oyama, M.-S. Chen, G.-J. Lee, K.-I. Kim, and T.-W. Kwon, "EFFECTS OF LOAD CHARACTERISTICS ON THE TRANSIENT STABILITY OF KEPCO'S SYSTEM A2 - AHN, UHI," in Power Systems and Power Plant Control 1989, ed Oxford: Pergamon, 1990, pp. 159-164.

[10] R.-C. S. P. D. S. Group, "Frequency Stability Evaluation Criteria for the Synchronous Zone of Continental Europe Requirements and impacting factors -," REE, Terna, TransnetBW, 50HertzTransmission, RTE, Swissgrid and Energinet.dk.March 2016.

[11] H. E. Joseph and e. al, "Use of frequency response metrics to assess the planning and operating requirements for reliable integration of variable renewable generation," Ernest Orlando Lawrence Berkeley National Laboratory, Berkeley,Dec. 2010.

[12] A. Ulbig, T. S. Borsche, and G. Andersson, "Analyzing Rotational Inertia, Grid Topology and their Role for Power System Stability," IFAC-PapersOnLine, vol. 48, pp. 541-547, 2015/01/01 2015.

[13] D. Gautam, V. Vittal, and T. Harbour, "Impact of Increased Penetration of DFIG-Based Wind Turbine Generators on Transient and Small Signal Stability of Power Systems," IEEE Transactions on Power Systems, vol. 24, pp. 1426-1434, 2009.

[14] S. Eftekharnejad, V. Vittal, G. T. Heydt, B. Keel, and J. Loehr, "Impact of increased penetration of photovoltaic generation on power systems," IEEE Transactions on Power Systems, vol. 28, pp. 893-901, 2013.

[15] X. Zhang, X. Cao, W. Wang, and C. Yun, "Fault ride-through study of wind turbines," Journal of Power and Energy Engineering, vol. 1, p. 25, 2013.

[16] R. J. Nelson, H. Ma, and N. M. Goldenbaum, "Fault ridethrough capabilities of siemens full-converter wind turbines," in 2011 IEEE Power and Energy Society General Meeting, 2011, pp. 1-5.

[17] J. Quintero, V. Vittal, G. T. Heydt, and Z. Hui, "The Impact of Increased Penetration of Converter Control-Based Generators on Power System Modes of Oscillation," IEEE Transactions on Power Systems, vol. 29, pp. 2248-2256, 2014.

[18] N. Miller, M. Shao, S. Pajic, and R. D’Aquila, "Western wind and solar integration study phase 3-frequency response and transient stability," 2014

[19] N. W. Miller, M. Shao, S. Venkataraman, C. Loutan, and M. Rothleder, "Frequency response of California and WECC under high wind and solar conditions," in 2012 IEEE Power and Energy Society General Meeting, 2012, pp. 1-8.

[20] A. Adrees, P. N. Papadopoulos, and J. V. Milanovic, "A framework to assess the effect of reduction in inertia on system frequency response," in Power and Energy Society General Meeting (PESGM), 2016, 2016, pp. 1-5.

[21] P. N. Papadopoulos and J. V. Milanović, "Probabilistic Framework for Transient Stability Assessment of Power Systems With High Penetration of Renewable Generation," IEEE Transactions on Power Systems, vol. 32, pp. 3078-3088, 2017.

[22] P.Kundur, Power System Stability \& Control. New York, London: McGraw Hill, 1994.

[23] H.-D. Chiang, J.-C. Wang, C.-T. Huang, Y.-T. Chen, and C.-H. Huang, "Development of a dynamic ZIP-motor load model from on-line field measurements," International Journal of Electrical Power \& Energy Systems, vol. 19, pp. 459-468, 1997.

[24] I. R. Navarro, O. Samuelsson, and S. Lindahl, "Automatic determination of parameters in dynamic load models from normal operation data," in Power Engineering Society General Meeting, 2003, IEEE, 2003, pp. 1375-1378.

[25] W. Jin-Cheng, C. Hsiao-Dong, C. Chung-Liang, L. Ah-Hsing, H. Chang-Horng, and H. Chiung-Yi, "Development of a frequencydependent composite load model using the measurement approach," IEEE Transactions on Power Systems, vol. 9, pp. 1546-1556, 1994.

[26] P. Pal and B. Chauduri, Robust Control in Power Systems. New York: Springer Science \& Business Media, 2005.

[27] W. R. E. M. T. Force, "WECC wind plant dynamic modeling guidelines," Western Electricity Coordinating Council Modeling and Validation Work Group, vol. 17, 2014.
[28] P. Sorensen, J. Fortmann, F. Buendia, J. Bech, A. Morales, and C. Ivanov, Final Draft International Standard IEC 61400-27-1, 2014.

[29] J. Fortmann, S. Engelhardt, J. Kretschmann, C. Feltes, and I. Erlich, "New generic model of DFG-based wind turbines for RMS-type simulation," IEEE Transactions on Energy Conversion, vol. 29, pp. 110-118, 2014.

[30] W. R. E. M. T. Force, "WECC PV Power Plant Dynamic Modeling Guide " May 2014.

[31] V. Krishnan, J. D. McCalley, S. Henry, and S. Issad, "Efficient database generation for decision tree based power system security assessment," IEEE Transactions on Power Systems, vol. 26, pp. 2319-2327, 2011. 